\title{
Pattern based Dimensionality Reduction Model for Age Classification
}

\author{
V.Vijaya Kumar, Ph.D \\ Dean-Computer Sciences (CSE \& \\ IT), Anurag Group of Institutions, \\ Hyderabad - 500088, A.P., India
}

\author{
Jangala. Sasi Kiran \\ Research Scholar \& Assoc. \\ Professor in CSE Dept, \\ MNR College of Engg. \& Tech, \\ Medak Dt -502294, A.P., India
}

\author{
Gorti Satyanarayana Murty \\ Research Scholar \& Assoc \\ Professor, Aditya institute of \\ Technology and Management, \\ Tekkalli-532 201, A.P., India
}

\begin{abstract}
The two most popular statistical methods used to measure the textural information of images are the Grey Level Cooccurrence Matrix (GLCM) and Texture Units (TU) approaches. The novelty of the present paper is, it combines TU and GLCM features by deriving a new model called "Pattern based Second order Compressed Binary (PSCB) image" to classify human age in to four groups. The proposed PSCB model reduces the given $5 \times 5$ grey level image into a 2 $\mathrm{x} 2$ binary image, while preserving the significant features of the texture. The proposed method intelligently compressed a $5 \times 5$ window into a $2 \times 2$ window and derived TU on them. Thus the derived TU also represents a TU of a $5 \times 5$ window. The TU of the proposed PSCB model ranges from 0 to 15 , thus it overcomes the previous disadvantages in evaluating TU's.
\end{abstract}

\section{Keywords}

GLCM features; Texture Unit; Pattern; compressed model;

\section{INTRODUCTION}

Aging has a significant impact on the appearance of a face [16] Consequently, face identification or verification can be significantly affected by variations in appearance due to age [17]. Currently, the research related on age estimation using face images is more important than ever, because it has many applications, such as an internet access control, underage cigarette-vending machine use, age-based retrieval of face images, age prediction systems for finding lost children and face recognition robust to age progression. In addition, the estimated age of consumers who look at billboards is used in age specific target advertising as consumer preferences differ greatly by age. To maintain identification/verification performance in the presence of age variation, some researchers have attempted to address this issue classifying the subjects age [18][19]. Unfortunately, age classification itself is very challenging due to the anatomical changes in the cranio-facial region, the bony portion of the head and the overlying softtissue caused by the aging progress [20].

Kwon and Lobo (1999) used facial feature detection and wrinkle detection to classify age to the three age groups: babies, young adults and seniors. Ueki et al. (2006) presented a classifier based on two phases using LDA (Linear Discriminant Analysis) and 2D-LDA to classify age. The benefit of their classifier is that it is robust under various lighting conditions. Ueki et al. (2006) experimented by using age ranges of 5 years, 10 years, and 15 years. The respective classification rates for each range were $46.3 \%, 67.8 \%$, and $78.1 \%$. The studies by Lanitis (2002) and by Lanitis et al. (2004) achieved roughly a 5-year mean error in the experiments where they used face images of people aged between 0 and 35 years. In the recent past many such classification strategies have been developed [21], [22]

The difficulty in automatic age estimation is mainly due to the specialty of aging effects on the face compared with other facial variations. The unique characteristics of aging variation mainly include: 1 . The aging progress is uncontrollable. 2. Personalized aging patterns. 3 . The aging patterns are temporal data.

When given a feature, feature classification steps are needed for age estimation. The feature classification can be divided into three approaches: the age group classification $[23,24,25,26]$, the single- level age estimation [27,28,29,30,31] and the hierarchical age estimation [27,32,33]. Age group classification is an approach that roughly predicts an age group, whereas single-level and hierarchical age estimations are focused on detailed age prediction. The single-level age estimation is to find the age label in the total data set. On the other hand, the hierarchical age estimation is a coarse-to-fine method used to find the age label in a pre-classified group's small data set. As facial aging is perceived differently in different age groups, age estimation in a specific age group provides a more accurate result. Moreover age estimation on a smaller age group simplifies the computational load.

\section{PROPOSED METHOD FOR AGE GROUP CLASSIFICATION OF} FACIAL IMAGES BASED ON GLCM FEATURES ON TU of PSCB MODEL

The proposed TU-PSCB model consists of seven steps. The block diagram of the proposed method is shown in Fig.1.

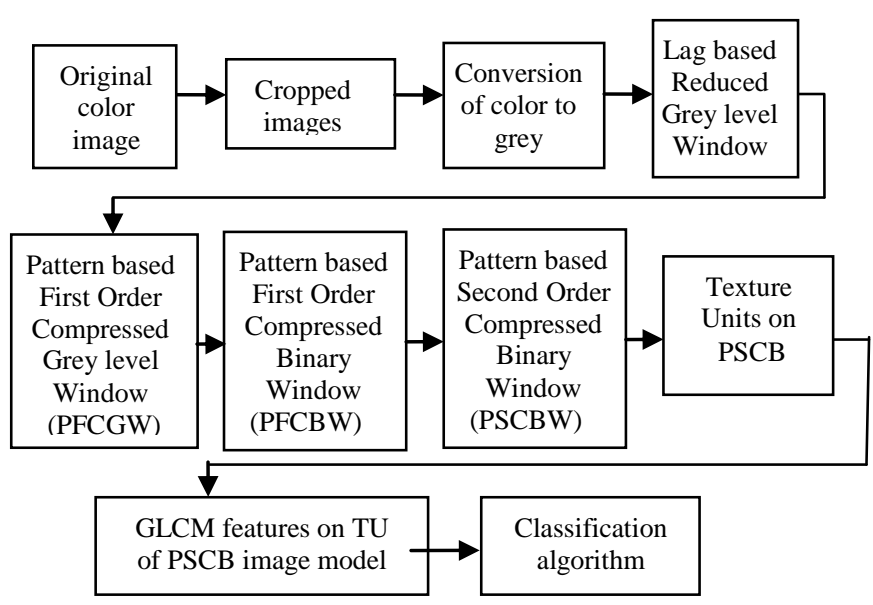

Fig. 1: Block diagram of the proposed PSCB image model. 
Step 1: The original facial image is cropped based on the location of two eyes in the first step as shown in Fig. 2.

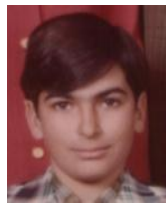

(a)

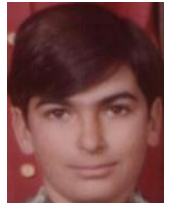

(b)
Fig. 2: a) Original image b) cropped image

Step 2: In the step 2, if the original facial images are color images then those are converted into a grey level facial texture image by using color quantization of 7-bit binary code, as explained below. In order to extract grey level features from colour information, the proposed method utilized the RGB colour space which quantizes the colour space into 7-bins to obtain 128 grey levels. The index matrix of 128 colour image is denoted as $\mathrm{C}(\mathrm{x}, \mathrm{y})$. The RGB quantization process is done by using 7-bit binary code of 128 colors as given in Eqn. (1.1) to (1.4).

$$
\begin{aligned}
& \mathrm{C}(\mathrm{x}, \mathrm{y})=16 * \mathrm{I}(\mathrm{R})+2 * \mathrm{I}(\mathrm{G})+\mathrm{I}(\mathrm{B}) \text { where } \\
& \mathrm{I}(\mathrm{R})=0,0 \leq \mathrm{R} \leq 16, \mathrm{I}(\mathrm{R})=\mathrm{i},((16 * \mathrm{i})+1) \leq \mathrm{R} \leq(16 *(\mathrm{i}+1)) \\
& \mathrm{i}=[1,2, \ldots, 7] \\
& \mathrm{I}(\mathrm{G})=0,0 \leq \mathrm{G} \leq 16, \mathrm{I}(\mathrm{G})=\mathrm{i},((16 * \mathrm{i})+1) \leq \mathrm{G} \leq(16 *(\mathrm{i}+1) \\
& \mathrm{i}=[1,2, \ldots, 6] \\
& \mathrm{I}(\mathrm{B})=0,0 \leq \mathrm{B} \leq 32, \mathrm{I}(\mathrm{B})=\mathrm{i},((32 * \mathrm{i})+1) \leq \mathrm{B} \leq(32 *(\mathrm{i}+1) \\
& \mathrm{i}=[1,2,3]
\end{aligned}
$$

Therefore, each value of $\mathrm{C}(\mathrm{x}, \mathrm{y})$ is a 7 bit binary code ranging from 0 to 127.

Step 3: Generation of Lag based Reduced Grey level Window (LRGW): Consider the $5 \times 5$ window of the image. Replace each pixel value by the absolute differences of that pixel value with central pixel value of the $5 \times 5$ window. If the absolute difference value is zero then corresponding pixel value is replaced with 2 , if the absolute difference value is in between 1 to lag value then corresponding pixel value is replaced with 1 other wise pixel value is replaced with zero. Lag value is chosen as the average value of the central $3 \times 3$ window of the $5 \times 5$ window. Apply this on entire image by non overlapping manner. By this the pixel values of entire image will have values either 2 or 1 or 0 . This forms the Lag based Reduced Grey level Window (LRGW).

Step4: Derivation of Pattern based First order Compressed Grey level Window (PFCGW): For reducing dimensionality for each $5 \times 5$ window, the proposed method adopted conditional pattern based approach. The $5 \times 5$ LRGW of the step 3 is shown in Fig. 3(a). The pixel values of $5 \times 5$ LRGW ranges from 0 to 2. The Fig. 3(b) represents the Pattern based First order Compressed Grey level window (PFCGW). The $\mathrm{g} 1, \mathrm{~g} 2, \ldots, \mathrm{g} 9$ pixel values of PFCGW represents the patterns of five horizontal, two diagonals, center vertical line and inner $3 \times 3$ window of LRGW, which are derived from the Eqn. (1.5) to $(1.13)$.

\begin{tabular}{|c|c|c|c|c|}
\hline $\mathrm{v}_{1}$ & $\mathrm{v}_{2}$ & $\mathrm{v}_{3}$ & $\mathrm{v}_{4}$ & $\mathrm{v}_{5}$ \\
\hline $\mathrm{v}_{6}$ & $\mathrm{v}_{7}$ & $\mathrm{v}_{8}$ & $\mathrm{v}_{9}$ & $\mathrm{v}_{10}$ \\
\hline $\mathrm{v}_{11}$ & $\mathrm{v}_{12}$ & $\mathrm{v}_{13}$ & $\mathrm{v}_{14}$ & $\mathrm{v}_{15}$ \\
\hline $\mathrm{v}_{16}$ & $\mathrm{v}_{17}$ & $\mathrm{v}_{18}$ & $\mathrm{v}_{19}$ & $\mathrm{v}_{20}$ \\
\hline $\mathrm{v}_{21}$ & $\mathrm{v}_{22}$ & $\mathrm{v}_{23}$ & $\mathrm{v}_{24}$ & $\mathrm{v}_{25}$ \\
\hline
\end{tabular}

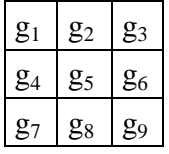

(b)

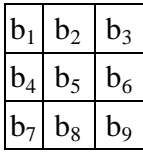

(c)
Fig. 3: (a) Local $5 \times 5$ LRGW (b) generated $3 \times 3$ PFCGW (c) generated $3 \times 3$ PFCBW.

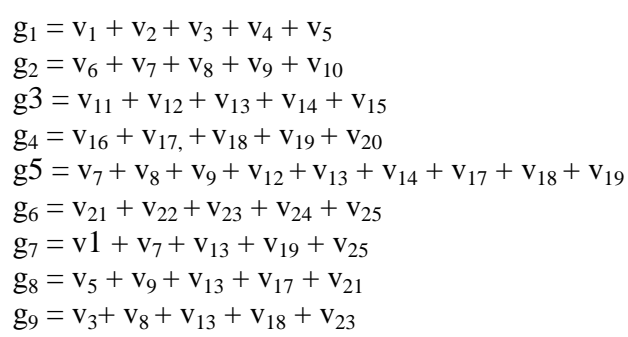

By observing the equations of $g_{1}, g_{2}, g_{3}, g_{4}, g_{6}, g_{7}, g_{8}$ and $g_{9}$ it is evident that that each of these pixel values can have a maximum value of 10 . Further the equation for g5 clearly indicates that $\mathrm{g} 5$ can have a maximum value of 18 . To convert them in to Pattern based First order Compressed Binary window (PFCBW) a condition is applied as given in Eqn. (1.14) and (1.15). By this the $3 \times 3$ "PFCGW" is converted in to binary window "PFCBW" as shown in Fig. 3(c).

if $g_{i}>=5$ then $g_{i}=1$ otherwise $g_{i}=0$

for $\mathrm{i}=1,2,3,4,6,7,8,9$

if $g_{5}>=9$ then $g_{5}=1$ otherwise $g_{5}=0$

Step 5: Generation of PSCBW of $2 \times 2$ from PFCBW of $3 \times$ 3: The PFCBW of $3 \times 3$ generated in the previous step consist pixel values only either 0 or 1 . This step reduces each of the 3 x 3 sub image of (PFCBW) into "Pattern based Second order Compressed Binary Window (PSCBW)" of $2 \times 2$ using the following conditional Eqn. as represented from (1.16) to (1.20) as shown in below Fig. 4.

\begin{tabular}{|l|l|l|}
\hline $\mathrm{b}_{1}$ & $\mathrm{~b}_{2}$ & $\mathrm{~b}_{3}$ \\
\hline $\mathrm{b}_{4}$ & $\mathrm{~b}_{5}$ & $\mathrm{~b}_{6}$ \\
\hline $\mathrm{b}_{7}$ & $\mathrm{~b}_{8}$ & $\mathrm{~b}_{9}$ \\
\hline
\end{tabular}

\begin{tabular}{|l|l|}
\hline $\mathrm{q}_{1}$ & $\mathrm{q}_{2}$ \\
\hline $\mathrm{q}_{3}$ & $\mathrm{q}_{4}$ \\
\hline
\end{tabular}

$$
\begin{aligned}
& \mathrm{q}_{1}=\mathrm{b}_{1}+\mathrm{b}_{5}+\mathrm{b}_{7} \\
& \mathrm{q}_{2}=\mathrm{b}_{3}+\mathrm{b}_{5}+\mathrm{b}_{7} \\
& \mathrm{q}_{3}=\mathrm{b}_{2}+\mathrm{b}_{5}+\mathrm{b}_{8} \\
& \mathrm{q}_{4}=\mathrm{b}_{4}+\mathrm{b}_{5}+\mathrm{b}_{6} \\
& \text { Where if } \mathrm{q}_{\mathrm{i}}>=2 \text { then } \mathrm{q}_{\mathrm{i}}=1 \\
& \text { otherwise } \mathrm{q}_{\mathrm{i}}=0 \text { for } \mathrm{i}=1 \text { to } 4
\end{aligned}
$$

By observing the equations of $\mathrm{q}_{1}, \mathrm{q}_{2}, \mathrm{q}_{3}$ and $\mathrm{q}_{4}$ it is evident that that each of these pixel values can have a maximum value of 4. Again to convert those in to Pattern based Second order Compressed Binary Window (PSCBW) of size $2 \times 2$, a condition is applied as given in equation (1.20). By this the 3 $\mathrm{x} 3 \mathrm{PFCBW}$ is compressed in to second order binary window of size 2 X 2 without losing significant features. By applying steps 3,4 and 5 on entire image on a $5 \times 5$ non-overlapped window basis, the entire texture image is converted into PSCB image model.

Step 6: Generation of TU on PSCB image model: The proposed method extracted local image information in the form of texture unit on each of the PSCBW. The proposed TU-PSCBW is different from usual texture unit represented in the literature, which is derived only on $3 \times 3$ windows. The 
proposed method intelligently compressed a $5 \times 5$ window into a $2 \times 2$ window and derived $\mathrm{TU}$ on them. Thus the derived TU also represents a TU of a $5 \times 5$ window. From each $2 \times 2$ PSCBW, TU value is calculated by using the Eqn. (1.21). This process is applied on entire image, then the image represents TU of PSCB image model.

$$
\sum_{\mathrm{k}=0}^{3} \operatorname{Power}(2, \mathrm{k}) * \mathrm{q}_{\mathrm{i}} \mathrm{i}=1,2,3,4
$$

TU of PSCBW consist the values ranging from o to 15 (totally 16) only. There is no unique way to label and order the texture units. To achieve unique way and rotational invariant property, the proposed TU on PSCBW considered the minimum value.

\begin{tabular}{|l|l|}
\hline 1 & 0 \\
\hline 1 & 0 \\
\hline
\end{tabular}

(a)

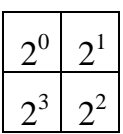

(b)

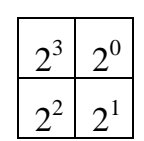

(c)

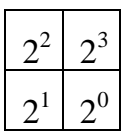

(d)

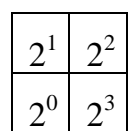

(e)
Fig. 5: Different ways of $2 \times 2$ neighborhoods.

The value of the TU changes by the representation of the weights. The TU can be calculated in 4 different ways for a 2 x 2 neighborhood is shown in Fig.5. That is for any $2 \times 2$ neighborhood one can generate four TU values. The TU value for the Fig. 5(a) in all four directions as represented in Fig. 5(b), 5(c),5(d) and 5(e) is given as 13, 14, 7 and 11 respectively.

The illustration process of generating the TU from original image of size $5 \times 5$ is shown in Fig. 6 .

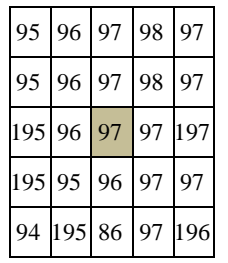

(a)

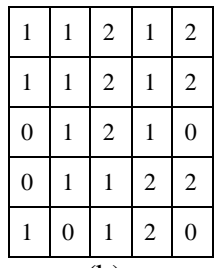

(b)

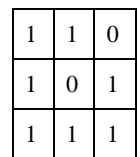

(c)

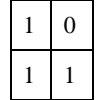

(d) $\quad(e)$
Fig.6: (a) Original 5 x 5 grey level window (b) a 5 x 5 LRGW

(c) a 3 x 3 PFCBW (d) $2 \times 2$ PSCBW (e) TU-PSCBW value.

Step 7: Generation of GLCM features on the derived TU of PSCB image model (PSCBI-TU): Grey Level Co-occurrence Matrix (GLCM) introduced by Haralick [3] attempt to describe texture by statistically sampling how certain grey levels occur in relation to other grey levels. One of the major inconveniences of Co-occurrence Matrix (CM) is the large range of its possible values (256 grey values) at the same time that these values are not correlated. It also requires more computation time. In general, the size of GLCM depends on grey level range of values of the image. To reduce grey values range in image and also to reduce overall dimension of the image, the present paper derived TU on PSCB image model. The PSCB image model reduces the overall dimensionality in to [2M/5 $x$ 2N/5], (Where image size is $(\mathrm{M} \mathrm{X} \mathrm{N})$ ). Further the TU of PSCB image model reduces the overall grey level range from 0 to 15 . Therefore the proposed TU-PSCB image is more suitable to evaluate GLCM features.

A set of GLCM features i.e; contrast, homogeneity, and correlation are extracted on the TU of PSCB facial images. They are represented from Eqn. (1.22) to (1.24). The proposed
TU of PSCB image model combines the merits of both statistical and structural information of images and thus represents complete information of the facial image.

$$
\begin{aligned}
& \text { contrast }=\sum_{\mathrm{i} j=\mathbb{0}}^{\mathbb{N}-1}-\ln \left(\mathbb{P}_{\mathrm{ij}}\right)^{2} \\
& \text { Homogenity }=\sum_{\mathrm{i} j=0}^{\mathrm{N}-1} \frac{\mathrm{P}_{\mathrm{ij}}}{1+(\mathrm{i}-\mathrm{i})^{2}} \\
& \text { Correlation }=\sum_{\mathrm{i} j=0}^{\mathbb{N}-1} \mathrm{P}_{\mathrm{ij}} \frac{(\mathrm{i}-\mu 1)\left(\mathrm{j}-\mu^{2}\right)}{\sigma^{2}}
\end{aligned}
$$

Where $\mathrm{P}_{\mathrm{ij}}$ is the pixel value in position (i,j) of the PSCBW-TU image, $\mathrm{N}$ is the number of grey levels in the image, $\mu=$ $\sum_{\mathrm{i}, \mathrm{j}=0}^{\mathrm{N}-1} \mathrm{i} \mathrm{P}_{\mathrm{ij}}$ mean of the image and $\sigma^{2}=\sum_{\mathrm{i}, \mathrm{j}=0}^{\mathrm{N}-1} \mathrm{P}_{\mathrm{ij}}(\mathrm{i}-$ $\mu)^{2}$ variance of the image.

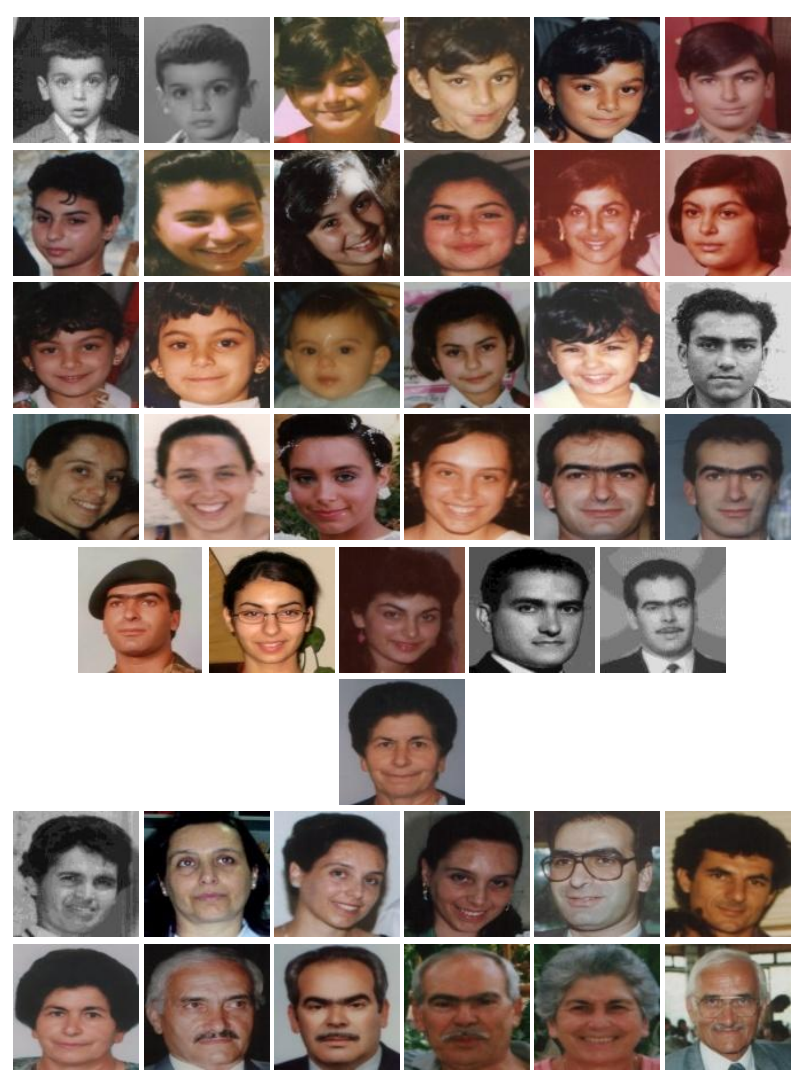

Fig. 7: FGNET aging database: 011A07, 011A05, 010A10, 010A09, 010A07b, 001A14, 019A07, 009A14, 009A13, 009A11, 008A16, 008A13, 010A05, 010A04, 010A01, 009A09, 009A05, 004A21, 002A29, 002A26, 002A23, 002A21, 001A29, 001A28, 001A22, 009A22a, 008A21, 004A28, 004A26, 006A36, 005A40, 011A40, 001A43b, 002A31, 001A33 007A37, 005A52, 005A49, 004A53, 004A51, 048A54, 006A61, 005A61, 004A63.

\section{RESULTS AND DISCUSSIONS}

The proposed GLCM feature on TU of PSCB image model is experimented with a database of the 1002 face images collected from FG-NET database, 500 face images collected from Google database and other 600 images collected from the scanned photographs. This leads a total of 2102 sample facial images. Sample images are shown in Fig.7. In the 
proposed method the sample images are grouped into four age groups of 0 to 15,16 to 30,31 to 60 , and above 60 . The GLCM features are extracted on TU of PSCB facial images of different age groups and the results are stored in the feature database. Feature set leads to representation of the training images. The GLCM features on TU of PSCB image model for four age groups of facial images are shown in Tables 1, 2, 3, and 4 respectively. Based on this information the proposed method derives an algorithm called "age classification based on TU of PSCB model" to efficiently classify the facial images into four groups which is represented in algorithm 1.

Table 1: GLCM feature set values on the derived TU of PSCB facial images with age group from 0 to15 years.

\begin{tabular}{|c|c|c|c|c|}
\hline S.No & $\begin{array}{c}\text { Image } \\
\text { Name }\end{array}$ & Contrast & Correlation & Homogeneity \\
\hline 1 & $001 \mathrm{~A} 02$ & 45.9345313 & 0.3633283 & 0.692991371 \\
\hline 2 & $001 \mathrm{~A} 05$ & 46.4697197 & 0.41410471 & 0.683276235 \\
\hline 3 & $001 \mathrm{~A} 08$ & 48.7631203 & 0.27325552 & 0.681913713 \\
\hline 4 & $001 \mathrm{~A} 10$ & 46.9281193 & 0.3500283 & 0.669533747 \\
\hline 5 & $001 \mathrm{~A} 14$ & 46.7345313 & 0.33716873 & 0.670538852 \\
\hline 6 & $002 \mathrm{~A} 03$ & 47.2345276 & 0.32657822 & 0.66689456 \\
\hline 7 & $002 \mathrm{~A} 04$ & 46.4453113 & 0.29325552 & 0.67564327 \\
\hline 8 & $002 \mathrm{~A} 05$ & 47.8712528 & 0.40610471 & 0.665437864 \\
\hline 9 & $007 \mathrm{~A} 01$ & 48.1073522 & 0.36753456 & 0.6908765 \\
\hline 10 & $002 \mathrm{~A} 07$ & 46.6343513 & 0.33716873 & 0.619821713 \\
\hline 11 & $002 \mathrm{~A} 12$ & 47.2348731 & 0.42134567 & 0.689533747 \\
\hline 12 & $002 \mathrm{~A} 15$ & 49.1109823 & 0.41410471 & 0.670288672 \\
\hline 13 & $008 \mathrm{~A} 06$ & 48.8087656 & 0.33716873 & 0.701546378 \\
\hline 14 & $008 \mathrm{~A} 12$ & 46.9341354 & 0.29098765 & 0.690895642 \\
\hline 15 & $008 \mathrm{~A} 13$ & 47.5643872 & 0.27325552 & 0.675298624 \\
\hline
\end{tabular}

Table 2: GLCM feature set values on the derived TU of PSCB facial images with age group from 16 to 31 years.

\begin{tabular}{|c|c|c|c|c|}
\hline S.No & $\begin{array}{c}\text { Image } \\
\text { Name }\end{array}$ & Contrast & Correlation & Homogeneity \\
\hline 16 & $001 \mathrm{~A} 16$ & 48.3467123 & 0.28674357 & 0.614537654 \\
\hline 17 & $001 \mathrm{~A} 18$ & 49.2087653 & 0.2789345 & 0.63765438 \\
\hline 18 & $001 \mathrm{~A} 19$ & 49.109659 & 0.2995802 & 0.64650099 \\
\hline 19 & $001 \mathrm{~A} 22$ & 48.0728629 & 0.30173542 & 0.62490603 \\
\hline 20 & $001 \mathrm{~A} 28$ & 48.8278028 & 0.3146596 & 0.645582946 \\
\hline 21 & $001 \mathrm{~A} 29$ & 47.8896544 & 0.31235644 & 0.64975435 \\
\hline 22 & $002 \mathrm{~A} 20$ & 48.9876534 & 0.2987569 & 0.63215674 \\
\hline 23 & $002 \mathrm{~A} 21$ & 46.7798753 & 0.31316548 & 0.64856352 \\
\hline 24 & $002 \mathrm{~A} 23$ & 49.5075635 & 0.32657432 & 0.612865935 \\
\hline 25 & $002 \mathrm{~A} 26$ & 47.8974325 & 0.29858456 & 0.606546322 \\
\hline 26 & $002 \mathrm{~A} 29$ & 48.8889765 & 0.31087574 & 0.599856487 \\
\hline 27 & $009 \mathrm{~A} 18$ & 47.0876789 & 0.28087378 & 0.62452678 \\
\hline 28 & $009 \mathrm{~A} 22 \mathrm{~b}$ & 47.3423577 & 0.31278462 & 0.598793422 \\
\hline 29 & $011 \mathrm{~A} 30$ & 49.0067543 & 0.28956345 & 0.64327468 \\
\hline 30 & $011 \mathrm{~A} 20$ & 48.0334217 & 0.31278735 & 0.59452783 \\
\hline
\end{tabular}

Table 3: GLCM feature set values on the derived TU of PSCB facial images with age group from 31 to 60 years.

\begin{tabular}{|c|c|c|c|c|}
\hline S.No & $\begin{array}{c}\text { Image } \\
\text { Name }\end{array}$ & Contrast & Correlation & Homogeneity \\
\hline 31 & $001 \mathrm{~A} 33$ & 55.7686567 & 0.24786431 & 0.59462119 \\
\hline 32 & $001 \mathrm{~A} 40$ & 57.0984567 & 0.29456425 & 0.613709382 \\
\hline 33 & $001 \mathrm{~A} 43 \mathrm{a}$ & 56.6678546 & 0.26745198 & 0.623144237 \\
\hline 34 & $001 \mathrm{~A} 43 \mathrm{~b}$ & 59.0672561 & 0.25648423 & 0.614934593 \\
\hline 35 & $013 \mathrm{~A} 34$ & 63.3367549 & 0.32316548 & 0.589734271 \\
\hline 36 & $013 \mathrm{~A} 41$ & 59.0007658 & 0.31657432 & 0.599562119 \\
\hline 37 & $013 \mathrm{~A} 44$ & 57.8723649 & 0.28858456 & 0.603709382 \\
\hline 38 & $014 \mathrm{~A} 40$ & 58.5643873 & 0.32095774 & 0.633144237 \\
\hline 39 & $014 \mathrm{~A} 42$ & 56.7785463 & 0.31298623 & 0.612493459 \\
\hline 40 & $001 \mathrm{~A} 43 \mathrm{a}$ & 60.7647059 & 0.23055462 & 0.569734271 \\
\hline 41 & $004 \mathrm{~A} 53$ & 57.0497657 & 0.25031893 & 0.609709382 \\
\hline 42 & $003 \mathrm{~A} 60$ & 54.284227 & 0.25402058 & 0.633144237 \\
\hline 43 & $004 \mathrm{~A} 51$ & 58.5272254 & 0.23141568 & 0.640934593 \\
\hline 44 & $002 \mathrm{~A} 31$ & 62.0067673 & 0.23102486 & 0.597873427 \\
\hline 45 & $007 \mathrm{~A} 37$ & 63.768543 & 0.2451297 & 0.652493459 \\
\hline 46 & $006 \mathrm{~A} 36$ & 64.5673252 & 0.26756823 & 0.659734271 \\
\hline 47 & $003 \mathrm{~A} 38$ & 60.7076754 & 0.30768562 & 0.600009382 \\
\hline 48 & $003 \mathrm{~A} 35$ & 63.9098675 & 0.2987456 & 0.633144237 \\
\hline 49 & $002 \mathrm{~A} 38$ & 64.0897655 & 0.28956433 & 0.631343476 \\
\hline
\end{tabular}

Table 4: GLCM feature set values on the derived TU of PSCB facial images with age above 60 years.

\begin{tabular}{|c|c|c|c|c|}
\hline S.No & $\begin{array}{c}\text { Image } \\
\text { Name }\end{array}$ & Contrast & Correlation & Homogeneity \\
\hline 50 & $006 \mathrm{~A} 69$ & 56.4833941 & 0.19715349 & 0.609899042 \\
\hline 51 & $003 \mathrm{~A} 62$ & 58.3499219 & 0.22749949 & 0.592662009 \\
\hline 52 & $003 \mathrm{~A} 61$ & 60.9599167 & 0.21450343 & 0.538748375 \\
\hline 53 & $004 \mathrm{~A} 53$ & 57.8763249 & 0.20765466 & 0.599734271 \\
\hline 54 & $004 \mathrm{~A} 62$ & 55.6786567 & 0.2278658 & 0.623144237 \\
\hline 55 & $004 \mathrm{~A} 63$ & 57.2989567 & 0.20781567 & 0.622493459 \\
\hline 56 & $005 \mathrm{~A} 61$ & 64.5667752 & 0.19875742 & 0.614934593 \\
\hline 57 & $006 \mathrm{~A} 61$ & 60.7276754 & 0.2067146 & 0.603709382 \\
\hline 58 & $006 \mathrm{~A} 67$ & 63.764583 & 0.18571258 & 0.641343476 \\
\hline 59 & $004 \mathrm{~A} 64$ & 64.5236752 & 0.1975562 & 0.609562119 \\
\hline 60 & $004 \mathrm{~A} 61$ & 58.5222754 & 0.16762925 & 0.613144237 \\
\hline
\end{tabular}

Algorithm 1: Age group classification algorithm based TU of PSCB image model.

Begin

If $(($ Contrast < 50) and (Homogeneity > 0.65))

Print ("age is in between 0 to 15 "); // Childhood

Else If ((Contrast < 50) and (Homogeneity < 0.65))

Print ("age is in between 16 to 30 "); // young age

Else If $(($ Contrast $>50)$ and (Correlation $>=0.23))$

Print ("age is in between 31 to 60 "); // middle age

Else If $(($ Contrast > 50) and (Correlation < 0.23$))$

Print ("age is above 60"); // old age

End

To evaluate the accuracy and significance of the present method, probe or test images are taken. On probe image, GLCM features are evaluated on TU of PSCB model of facial image. As an experimental case 40 face samples, randomly collected from FG-NET, Google database and some Scanned images are considered. The features extracted on the facial images with their successful classification results using present scheme is given in Table 5. The classification percentage of three datasets is shown in Table 6 and classification graph of three datasets are shown in Fig. 8. 
Table 5: Age classification table with GLCM feature of test data on the proposed PSCBW-TU model.

\begin{tabular}{|c|c|c|c|c|c|}
\hline $\begin{array}{l}\text { S. } \\
\text { No }\end{array}$ & $\begin{array}{l}\text { Image } \\
\text { Name }\end{array}$ & Contrast & $\begin{array}{c}\text { Correlati } \\
\text { on }\end{array}$ & Homogeneity & $\begin{array}{l}\text { Classified } \\
\text { age group }\end{array}$ \\
\hline 1 & 001A08 & 46.5311 & $\mid 0.29553561$ & 0.67564327 & $0-15$ \\
\hline 2 & $002 \mathrm{~A} 18$ & 47.8897 & 0.31235644 & 0.64975435 & $16-30$ \\
\hline 3 & $003 \mathrm{~A} 20$ & 48.8977 & 0.2957869 & 0.6327644 & $16-30$ \\
\hline 4 & 005A24 & 47.9646 & 0.33215644 & 0.649457135 & $16-30$ \\
\hline 5 & 063A05 & 49.8923 & 0.40715664 & 0.674823881 & $0-15$ \\
\hline 6 & 064A16 & 47.9997 & 0.35321644 & 0.64579435 & $16-30$ \\
\hline 7 & 064A59 & 56.7855 & 0.26345314 & 0.623763 & $31-60$ \\
\hline 8 & $065 \mathrm{~A} 03$ & 49.8226 & 0.41665362 & 0.672384881 & $0-15$ \\
\hline 9 & 067A18 & 47.9654 & 0.31675325 & 0.645435 & $16-30$ \\
\hline 10 & 022A28 & 48.6534 & 0.29231876 & 0.635612574 & $16-30$ \\
\hline 11 & $023 \mathrm{~A} 29$ & 47.4332 & 0.36542836 & 0.62316735 & 16-30 \\
\hline 12 & 024A30 & 48.3425 & 0.29324569 & 0.63215674 & 16-30 \\
\hline 13 & $025 \mathrm{~A} 48$ & 56.7855 & 0.261976 & 0.623134763 & $31-60$ \\
\hline 14 & 027A30 & 56.6662 & 0.26564276 & 0.6144237 & $31-60$ \\
\hline 15 & 017A62 & 63.8302 & $\mid 0.1864355$ & 16756 & $>60$ \\
\hline 16 & 018A34 & 59.0008 & 0.31632 & 0.59900772 & $31-60$ \\
\hline 17 & 020A36 & 57.2786 & 0.29990846 & \begin{tabular}{|l}
0.590709382 \\
\end{tabular} & $31-60$ \\
\hline 18 & 025A59 & 58.5644 & 0.32095774 & 0.633144237 & $31-60$ \\
\hline 19 & Sci-1 & 48.7677 & 0.2723561 & 0.681914493 & $0-15$ \\
\hline 20 & Sci-2 & 57.4654 & 0.30000908 & 0.600040938 & $31-60$ \\
\hline 21 & Sci-3 & 47.5644 & 0.31453288 & 0.649967535 & 16-30 \\
\hline 22 & Sci-4 & 57.7666 & 0.25423498 & 0.627334763 & $31-60$ \\
\hline 23 & Sci-5 & 56.6233 & 0.26745198 & 0.623144237 & $31-60$ \\
\hline 24 & Sci-6 & 47.3745 & $\mid 0.30345644$ & 0.644328675 & $16-30$ \\
\hline 25 & Sci-7 & 48.5342 & 0.30987569 & 0.635327854 & $16-30$ \\
\hline 26 & Sci-8 & 47.1238 & 0.30564336 & \begin{tabular}{|l|l|}
0.634253674 \\
\end{tabular} & 16-30 \\
\hline 27 & $20-2$ & 48.3421 & 0.29651239 & \begin{tabular}{|l|l|}
0.643215674 \\
\end{tabular} & 16-30 \\
\hline 28 & $25-1$ & 60.0008 & 0.32557432 & \begin{tabular}{|l|}
0.599562231 \\
\end{tabular} & $31-60$ \\
\hline 29 & $25-2$ & 58.9077 & 0.28856 & \begin{tabular}{|l}
0.600739382 \\
\end{tabular} & $31-60$ \\
\hline 30 & $25-3$ & 58.5644 & 0.325774 & 0.613344237 & $31-60$ \\
\hline 31 & $40-6$ & 49.0008 & 0.30054743 & 0.599562119 & $31-60$ \\
\hline 32 & $40-1$ & 57.8724 & 0.28858456 & 0.673109382 & $31-60$ \\
\hline 33 & $40-2$ & 58.5644 & 0.32095774 & 0.633144237 & $31-60$ \\
\hline 34 & $40-3$ & 57.7779 & 0.26124233 & 0.689453733 & $31-60$ \\
\hline 35 & $40-4$ & 56.5462 & \begin{tabular}{|l|}
0.2671976 \\
\end{tabular} & 0.687653488 & $31-60$ \\
\hline 36 & $40-5$ & 64.7646 & 0.18571258 & 0.641343476 & $>60$ \\
\hline 37 & $35-1$ & 56.8545 & 0.251976 & 0.623143348 & $31-60$ \\
\hline 38 & $50-1$ & 56.2318 & 0.267476 & 0.637334763 & $31-60$ \\
\hline 39 & $50-2$ & 63.5643 & 0.2413375 & 0.631221343 & $>60$ \\
\hline 40 & $50-3$ & 64.8302 & 0.18125758 & \begin{tabular}{|l|l|l|l} 
\\
\end{tabular} & $>60$ \\
\hline
\end{tabular}

Table 6: \% age group classification on three datasets by the proposed PSCB image model.

\begin{tabular}{|c|c|c|c|}
\hline Image Dataset & $\begin{array}{c}\text { FG-NET } \\
\text { database }\end{array}$ & $\begin{array}{c}\text { Google } \\
\text { database }\end{array}$ & $\begin{array}{c}\text { Scanned } \\
\text { images }\end{array}$ \\
\hline Childhood (0-15) & $100.00 \%$ & $92.50 \%$ & $90.00 \%$ \\
\hline Young adults (16-31) & $97.50 \%$ & $95.00 \%$ & $93.00 \%$ \\
\hline Middle Adults (31-60) & $100.00 \%$ & $92.50 \%$ & $92.50 \%$ \\
\hline 0ld Adults (> 60) & $97.50 \%$ & $95.00 \%$ & $93.00 \%$ \\
\hline
\end{tabular}

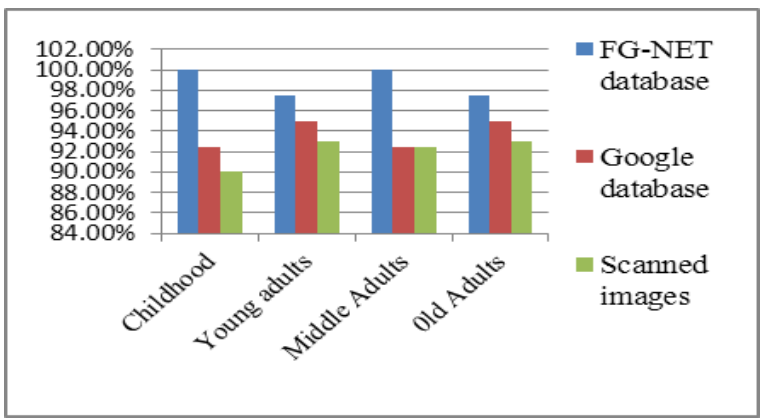

Fig. 8: \% age classification graph of three datasets based on algorithm 1.

\section{COMPARISON WITH OTHER EXISTING METHODS}

The proposed method is compared with geometric feature based age classification system [1] and image-based agegroup classification method [2] methods. The percentage of classification rates of the proposed method and other existing methods $[1,2]$ are listed in Table 7 . The Table 7 clearly indicates that the proposed method yields better classification rate when compared with existing methods.

Fig. 9 shows the comparison chart of the proposed method with the other existing methods of Table 7.

Table 7: \% mean classification rates of the proposed

PSCB image model and other existing methods.

\begin{tabular}{|l|c|c|c|}
\hline \multicolumn{1}{|c|}{$\begin{array}{c}\text { Image } \\
\text { Dataset }\end{array}$} & $\begin{array}{c}\text { Geometric } \\
\text { feature based } \\
\text { age classification } \\
\text { system }\end{array}$ & $\begin{array}{c}\text { Image-based } \\
\text { age-group } \\
\text { classification } \\
\text { method }\end{array}$ & $\begin{array}{c}\text { Proposed } \\
\text { PSCB image } \\
\text { model }\end{array}$ \\
\hline Childhood & $76.00 \%$ & $90.15 \%$ & $95.00 \%$ \\
\hline Young adults & $76.50 \%$ & $89.50 \%$ & $92.50 \%$ \\
\hline Middle Adults & $76.00 \%$ & $88.50 \%$ & $95.00 \%$ \\
\hline Old Adults & $75.50 \%$ & $90.15 \%$ & $92.50 \%$ \\
\hline
\end{tabular}

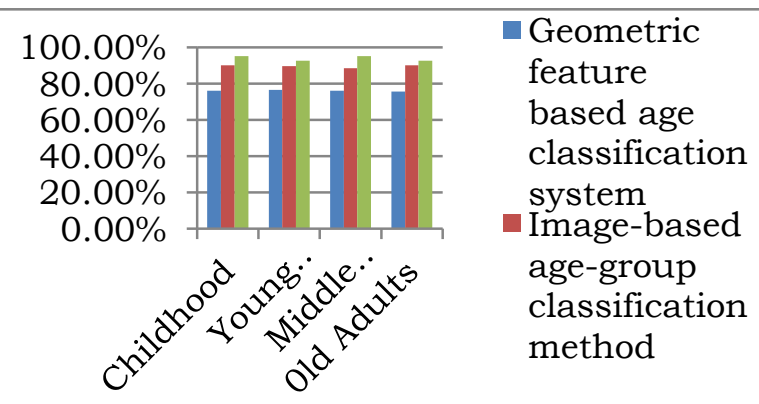

Fig. 9: Comparison graph of proposed method with other existing methods.

\section{SUMMARY}

This paper presented a novel approach for age group classification, including childhood (0-15), young adults (1630 ), middle adult (31-60) and the old adults (above 60) based on GLCM features on the derived Texture units of the PSCB image model. The novelty of the proposed PSCB image model is, it reduced the overall dimensionality in to $[2 \mathrm{M} / 5 \mathrm{x}$ 2N/5], (Where image size is $(\mathrm{M} \mathrm{X} \mathrm{N})$ ). The proposed TUPSCBW is different from usual texture unit represented in the literature, which is derived only on $3 \times 3$ windows. The proposed method intelligently compressed a $5 \times 5$ window into a $2 \times 2$ window and derived TU on them. Thus the derived TU also represents a $\mathrm{TU}$ of a $5 \times 5$ window. There is no unique 
way to label and order the texture units. To achieve unique way and rotational invariant property, the proposed TU on PSCBW considered the minimum value. In the previous approaches, the TU ranges from 0 to 3561 [4], 0 to 2020 [5, 6, $7,8], 0$ to $255[10,11,12,13,14,15]$ and 0 to 79 [9]. To overcome this, the proposed model of TU of PSCB image reduced the overall TU's from 0 to 15 . Therefore the proposed TU-PSCB image is more suitable to evaluate GLCM features than the previous approaches. For a precise, significant and accurate classification, the present study evaluated only three GLCM features on the derived TU of PSCB facial images. The present method is also tested for three FG-NET, Google aging database and Scanned images. The performance of the present system is more effective for the FG-NET aging database when compare with Google Images and scanned images. The average recognition rate is $93.33 \%$.

\section{ACKNOWLEDGEMENTS}

The authors would like to express their gratitude to Dr. P. Rajeshwar Reddy, Chairman, Anurag Group of Institutions (AGOI), Hyderabad for providing necessary infrastructure for Centre for Advanced Computational Research (CACR) at AGOI, which is bringing various research scholars across the nation to work under one proof. The CACR is providing a research platform for exchanging and discussing various views on different research topics in CSE. Authors extended their gratitude to Managements of MNR College of Engg. \& Technology, Sangareddy, A.P. India and Aditya Institute of Technology and Management (AITAM), Tekkali, A.P. India for promoting the young staff members towards research activities.

\section{REFERENCES}

[1] Lin-Lin Shen, Zhen Ji, "Modeling Geometric Features for Face Based Age Classification", Proceedings of the Seventh International Conference on Machine Learning and Cybernetics, Kunming, 12-15 July 2008.

[2] Vi-Wen Chen, Meng-Ju Han and Kai-Tai Song, YuLunHo, "Image-Based Age-Group Classification Design Using Facial Features", International Conference on System Science and Engineering, IEEE 2010.

[3] Haralick RM, Shanmugan K and Dinstein I, "Textural features for image classification," IEEE Trans. Sysr., Man., Cybern., Vol. SMC-3, pp.610-621, 1973.

[4] Wang L., He D.C., "Texture classification using texture spectrum, Pattern Recognition,” vol. 23(8), pp: 905-910, 1990.

[5] Wiselin Jiji G., "Colour texture classification for Human Tissue Images," Applied Soft Computing, vol. 11, pp: 1623-1630, 2011.

[6] Wiselin Jiji G., Ganesan L., "A new approach for unsupervised segmentation," Applied Soft Computing, vol.10, pp: 689-693, 2010.

[7] Wiselin Jiji G., Ganesan L., "Comparative analysis of colour models for colour textures based on feature extraction," Int. Jour. of Soft computing, vol.2 (3), pp: 361-366, 2007.

[8] Aina Barceloa, Eduard Montseny, Pilar Sobrevilla, "Fuzzy texture unit and fuzzy texture spectrum for texture characterization," Fuzzy Sets and Systems, vol.158 pp: 239-252, 2007.
[9] Sujatha B., VijayaKumar V., Chandra Mohan M., "Rotationally invariant texture classification using LRTM based on fuzzy approach," Int. Journal of Computer Applications (IJCA), vol.33, pp: 1-5, 2011.

[10] Chen C. H., Pau L. F., and Wang P. S. P., "Texture analysis: in Handbook of Pattern Recognition and Computer Vision," Eds, Singapore: World Scientific, pp. 235-276, 1993.

[11] Dong-Chen $\mathrm{He}$ and $\mathrm{Li}$ Wang, "Texture feature extraction from texture spectrum," pp:1987-1990, 1990.

[12] Dong-Chen He And Li Wang, "Texture unit, texture spectrum, and texture analysis," IEEE Transactions on Geo-science and Remote Sensing, vol.28, pp: 509-512, 1990.

[13] He D.C, Wang L., "Unsupervised textural classification of images using the texture spectrum," Pattern recognition papers, vol.25 (3), pp: 247-255, 1992.

[14] A.Gunay, V.V.Nabiyev, Automatic age classification with LBP, in: 23rdInterna-National Symposium on Computer and Information Sciences, ISCIS 008 (2008)14.

[15] He D.C., Wang L., and Guibert J., "Texture discrimination based on an optimal utilization of texture features", Pattern Recognition, no 2, pp:141-146, 1988.

[16] Wang L., He D.C., “Texture classification using texture spectrum, Pattern Recognition," vol. 23(8), pp: 905-910, 1990.

[17] D. Enlow. The handbook of facial growth (2nd ed.) London: W.B. Saunders, 1982.

[18] H. Dehon and S. Bredart. An 'other-race' effect in age estimation from faces. Perception, 30(9):1107-1113, 2001.

[19] Y. Fu, G. Guo, and T.S. Huang. Age synthesis and estimation via faces: A survey. IEEE Trans. Pattern Anal. Mach. Intell., 32:1955-1976, November 2010.

[20] C. Shan. Learning local features for age estimation on real-life faces. In Proc. of ACM International Workshop on Multimodal Pervasive Video Analysis, pages 23-28, 2010

[21] M.A. Taister, S.D. Holliday, and H.I.M. Borrman Comments on facial aging in law enforcement investigation. Foren. Sci. Comm., 2(2):11, 2000.

[22] Y. Bando, T. Kuratate, and T. Nishita, "A Simple Method for Modeling Wrinkles on Human Skin," Proc. 10th Pacific Conf. Computer Graphics and Applications, pp. 166-175, 2002

[23] Kwon, Y. H. and da Vitoria Lobo, N.,"Age classification from facial images," Proc. IEEE Conf. on Computer Vision and Pattern Recognition, Seattle, Washington, U. S. A., pp. $762-767$ (1994).

[24] WenBingHorng, ChengPingLee, ChunWenChen, Classification of age groups based on facial features, Tamkang Journal of Science and Engineering4 (3) (2001) 183-192.

[25] H.C.Lian, B.L.Lu, Age estimation using a min-max modular support vector machine, in: 12th International 
Conference on Neural Information Processing (ICONIP 2005)(2005)83-88.

[26] FengGao, HaizhouAi, Face age classification on consumer images with gabor feature and fuzzy LDA method, Lecture Notes in Computer Science, in: Proceedings of the Third International Conference on Advances in Biometrics 5558 (2009)132-141.

[27] Andreas Lenities, Christina Drag nova, Chris Christodoulou, Comparing different classifiers for automatic age estimation, IEEE Transactions on Systems, Man, and Cybernetics,PartB:Cybernetics34(1)(2004)621-628.

[28] JinliSuo, TianfuWu, SongchunZhu, ShiguangShan, XilinChen, WenGao, Design sparse features for age estimation using hierarchical face model, in: Proceedings of the Eighth IEEE International Conference on Automatic Face\& Gesture Recognition, FG 008. (2008)17-19.

[29] ShuichengYan, HuanWang, XiaoouTang, T.S.Huang, Learning auto-structured regressed from uncertain nonnegative labels, in: IEEE 11th International Conference on Computer Vision, ICCV (2007).

[30] GuodongGuo, YunFu, C.R.Dyer, T.S.Huang, Imagebased human age estimation by manifold learning and locally adjusted robust regression, IEEE Transactions on Image Processing17(7)(2008)1178-1188.

[31] Andreas Lanitis, Christopher J.Taylor, TimothyF. Cootes, Toward automatic simulation of aging effects on face images, IEEE Transactions on Pattern Analysis and Machine Intelligence24(4)(2002)442-455.

[32] G.-D.Guo, G.Mu, Y.Fu, C.R.Dyer, T.S.Huang, A study on automatic age estimation using a large Database, In: Proceedings of the IEEE Conference on Computer Vision (ICCV’09)(2009).

[33] KhoaLuu, KarlRicanekJr, TienD.Bui, ChingY.Suen, Age estimation using active appearance models and support vector machine regression, in: Proceedings of the IEEE Third International Conference on Biometrics: Theory, Applications, and Systems (2009)1-5.

\section{AUTHORS PROFILE}

Dr. Vakulabharanam Vijaya Kumar is working as DeanComputer Sciences (CSE \& IT) at Anurag Group of Institutions (AGOI), Hyderabad. He received integrated M.S.Engg, in CSE from USSR in 1989. He received his Ph.D. degree in Computer Science from Jawaharlal Nehru Technological University (JNTU), Hyderabad India in 1998.He has served JNT University for 13 years as Assistant Professor and Associate Professor. He is also the head for Centre for Advanced Computational Research (CACR) at AGOI, Hyderabad where research scholars across the state are working. He has received best researcher and best teacher award. His research interests include Image Processing, Pattern Recognition, Digital Water Marking, Cloud Computing and Image Retrieval Systems. He is the life member of CSI, ISCA, ISTE, IE (I), IETE, ACCS, CRSI, IRS and REDCROSS. He has published more than 120 research publications till now in various National, International conferences, and Journals and guided 14 research scholars for $\mathrm{PhD}$. He has also established and also acted as a Head, Srinivasa Ramanujan Research Forum (SRRF) at GIET, Rajahmundry, India from May 2006 to April 2013 for promoting research and social activities.

J. Sasi Kiran Graduated in B.Tech from JNTU in 2002. He received Masters Degree in M.Tech. from Bharath University, Chennai, in 2005 and pursuing Ph.D from University of Mysore, Mysore in CSE under the guidance of Dr. V. Vijaya Kumar. At present he is pursuing his research at Centre for Advanced Computational Research (CACR) of Anurag Group of Institutions (AGOI), Hyderabad. He served as an Associate Professor in Vidya Vikas Institute of Technology, Hyderabad from 2005 to 2013 and working as Associate Professor in CSE Dept. in MNR College of Engg. \& Tech, Sangareddy, Medak Dt, A.P, India. His research interests include Image Processing, Cloud Computing and Image Retrieval Systems. $\mathrm{He}$ has published research papers in various National, International conferences, proceedings and Journals. He is a life member of CSI, IE, ISTE, ISC, IAE and management committee member of CSI. He has received significant contribution award from CSI India in 2012.

Gorti Satyanarayana Murty received Masters Degree in M.Tech. from JNT University, Kakinada and pursuing Ph.D from Acharya Nagarjuna University ,Guntur in Computer Science \& Engineering under the guidance of Dr. V. Vijaya Kumar. At present he is pursuing his research at Centre for Advanced Computational Research (CACR) of Anurag Group of Institutions (AGOI), Hyderabad. $\mathrm{He}$ is working as Associate Professor in Aditya Institute of Technology and Management, Tekkali, Srikakulam Dt, A.P, India since 2005. His research interests include Image Mining and facial image and texture analysis. He has published research papers in various National, International conferences, proceedings and Journals. He is a life member of ISTE, CSI. 